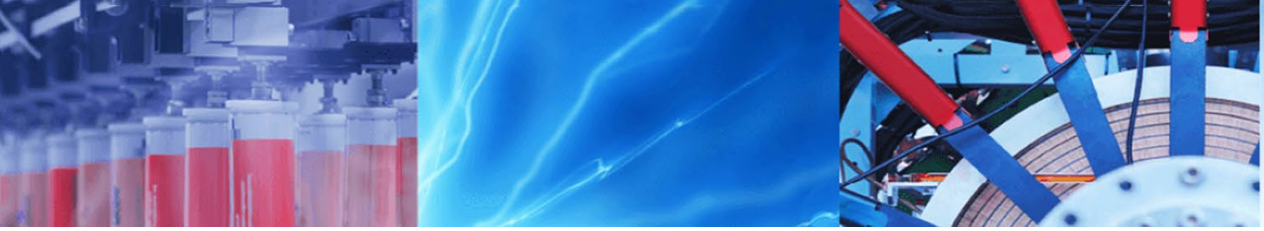

Research Article

\title{
Design modifications and multilayer impact in the electronic parameters of printed graphene patch antenna
}

\author{
Prasanna $\operatorname{Ram}^{1}{ }^{1} \cdot$ R. Rachel Jeeva Light ${ }^{1} \cdot$ Kushal Nomula $^{1}$
}

Received: 2 July 2019 / Accepted: 18 October 2019 / Published online: 26 October 2019

(c) Springer Nature Switzerland AG 2019

\begin{abstract}
The stack antenna technique used to improve the antenna characteristics of the printed patch antenna structures. The method of stacking varies for each material. In this work we used graphene as the radiating material. The improvement in the parameters is achieved by edge truncation and ground plane optimization techniques. The main factor to affect the stacking is the curing temperature and the heat absorbing nature of the substrate and air gap between layers. In this work we have experimented and analysed the effect of multilayer stacking on printed antenna structures and its effect on the antenna performance. The antenna is designed for $2.45 \mathrm{GHz}$ ISM Band applications and the gain is more than $+5 \mathrm{~dB}$. In this paper we tried to replace the copper with multilayer graphene based printed structure.
\end{abstract}

Keywords Graphene $\cdot$ Printing technique $\cdot$ Patch antenna $\cdot$ Stack structures $\cdot$ Radiation pattern · Gain

\section{Introduction}

Microstrip antennas are low profile antennas, that are conformable to planar and non-planar surfaces, simple and inexpensive to manufacture using modern printed-circuit technology, mechanically robust when mounted on rigid surfaces, compatible with MMIC designs, and when the particular patch shape and mode are selected, they are very versatile in terms of resonant frequency, polarization, pattern, and impedance [1]. Compared to conventional antennas MSA have some disadvantages such as; Narrow bandwidth, Lower Gain and low power handling capability.

Many techniques have been introduced in the design of MSA to overcome the disadvantages like narrow bandwidth and low gain. One among them is reducing the size of the ground plane. Reducing the ground plane changes the antenna parameters especially the Bandwidth. Bandwidth of the antenna is increased [2] by decreasing the ground plane to one third of the substrate size. This reduction in ground plane leads to increase the back lobes and also changes the operating frequency of the patch antenna. This change in antenna parameters like resonant frequency which is an important parameter due to partial ground plane can be rectified by edge truncation technique [3]. Reduction in the ground plane also provides better impedance matching [4]. Ground plane slots [5] and ground plane reduction optimizes the operating frequency range of the antenna. Ground Plane reduction minimizes the material used for printing patch antenna thereby decreasing overall manufacturing cost.

To rectify the changes in antenna parameters due to ground plane reduction techniques like truncation and slots in patches can be used. In this paper edge truncation technique is used for optimizing the antenna parameters. Truncation improves gain, bandwidth [6] and directivity [7]. Truncation can be done by removing a portion of patch from edges or corners. This part can be

Prasanna Ram, prasannaram88@gmail.com; R. Rachel Jeeva Light, racheljeevalight@gmail.com; Kushal Nomula, kushal.nomula@gmail.com | ${ }^{1}$ Department of Electronics and Communication Engineering, Vel Tech Rangarajan Dr. Sagunthala R\&D Institute of Science and Technology, Avadi 600062, India. 
of any shape and size. Shape of the truncation affects the axial ratio bandwidth of a circularly polarized antenna [8]. Edge truncation affects the impedance bandwidth of the antenna [9] which is used in this paper.

Recently, printed electronics is an interesting field of research which provides many advantages such as ease of fabrication, light weight etc. Under this category material based printed antennas are of great interest. Conventional patch antennas use copper or aluminium as the radiating patch. In this paper conventional copper radiating patch is replaced with graphene because of its extremely good electrical and thermal properties [10]. For graphene antenna printing applications, spraying is a less reported method, suffering from lacking of uniformity in films. Inkjet-printing and doctor blade methods are complementary, the former having high accuracy and cost, in contrast to the latter [11].

In printed antennas single layer and multilayer printed antennas [12] shows difference in the antenna parameters which are discussed in this paper. Multilayer stacking of different feeding patches increases the axial ratio (AR) bandwidth [13]. Gain, which is an important factor for satellite applications, can be increased by increasing the area of the patch since gain in directly proportional to the aperture area of the antenna. Instead of increasing the size of the patch array can be used which also increases the overall size of the antenna. A solution to increase gain without increasing the size of the antenna [14] is stacking of patches one above the other vertically. Stacking with air gap increases the bandwidth $[15,16]$ and also gain.

In this work edge truncated patch antenna is designed, simulated and fabricated using both copper and graphene and the parameters were studied. Double layer graphene is also fabricated and the results were discussed.

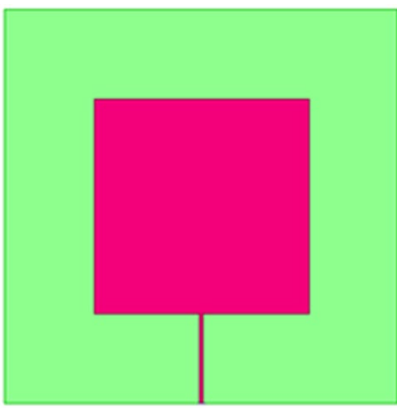

(a)

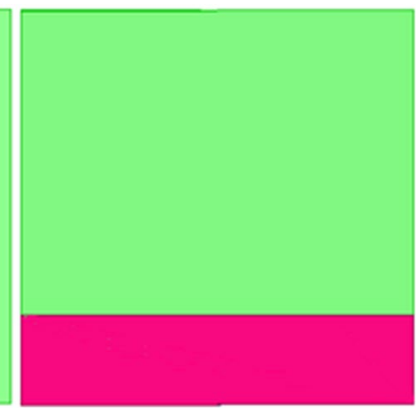

(b)

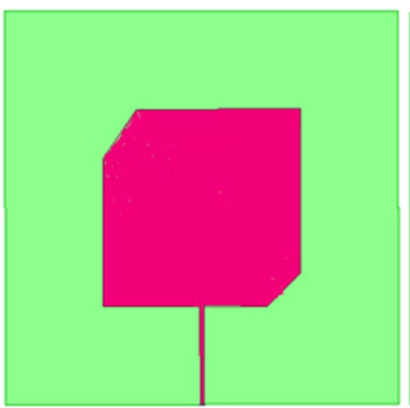

(a)

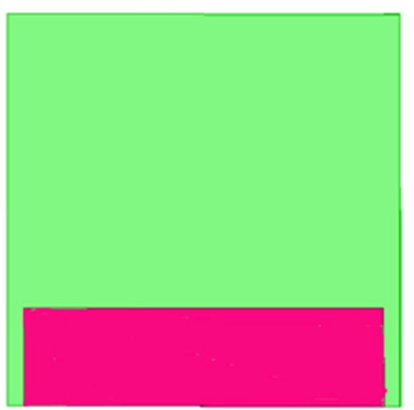

(b)
Fig. 2 Truncated design a Top radiating patch, b bottom Ground plane

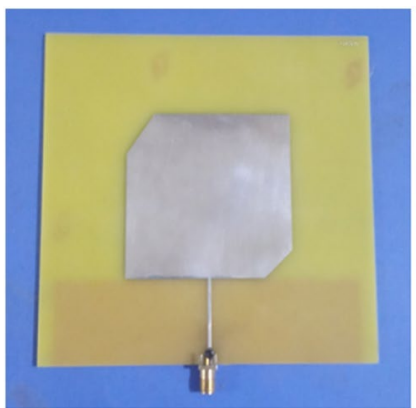

(a)

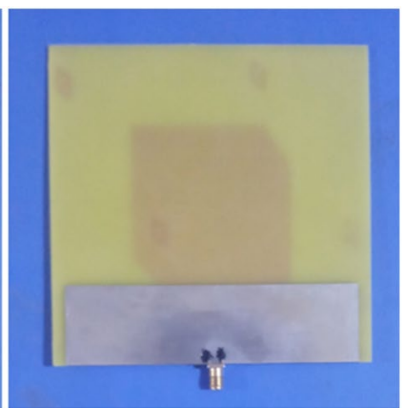

(b)
Fig. 1 a Top radiating patch, $\mathbf{b}$ bottom ground plane 


\subsection{Fabricated prototype}

Figure 3 shows the copper fabricated antenna in which the copper thickness is $0.035 \mathrm{~mm}$. To prevent the oxidation of copper the antenna is coated with $\mathrm{Sn}-\mathrm{Pb}$. The prototype is measured using Key sight Handheld Vector Network Analyzer N9923A. Two techniques to attach the SMA connector with antenna were examined in this work. One is conventional soldering method and the other one is using polymer based conductive bonding composite for attaching the SMA connector.

Graphene antenna is fabricated using doctor blade technique [11] which is one of the suitable methods for graphene printing is shown in Fig. 4. Single layer printing and double layer printing were done and the parameters were measured. The second layer is stacked vertically above the first layer without any substrate in between and also without any air gap. The material used for the purpose is of Graphene conductive ink type. The particles vary from 6 to $600 \mathrm{~nm}$.

The fabrication is achieved by low cost printing method. The single layer is printed with a thickness of about $300 \mu \mathrm{m}$, double layer will be $600 \mu \mathrm{m}$. The variation in the thickness may be result of uneven temperature of sintering environment. So for the curing process the temperature is maintained at $80-85^{\circ} \mathrm{C}$. The CADD model generated using the Ansoft HFSS will be printed over the substrate. The problem lies with connecting the SMA-F connectors with the printed patch over the substrate. This will be achieved by using the lead free silver based polymer composites.

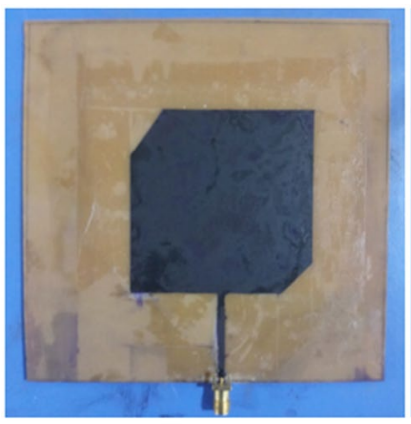

(a)

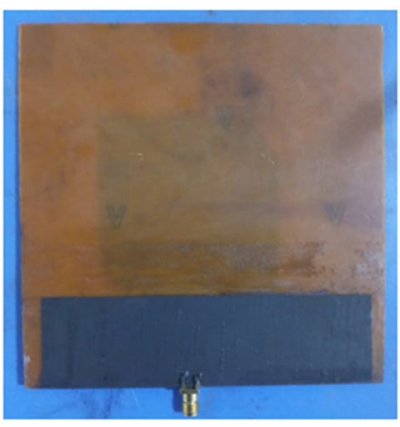

(b)
The prototype antenna is measured for its characteristics using Key sight Handheld Vector Network Analyzer N9923A. The nature of the Graphene material used for the fabrication are Purity is $99 \%$, Average Thickness is $3-8 \mathrm{~nm}$, Average Lateral Dimension is $5-10 \mu \mathrm{m}$, Number of Layers, 3-6 Layers, Surface area is $180 \mathrm{~m}^{2} / \mathrm{g}$, Strength is $130 \mathrm{GPa}$, Thermal, Conductivity is $5000 \mathrm{~W} / \mathrm{m}$ k, Electrical Conductivity is $10^{*} 10^{7}$ Siemens $/ \mathrm{m}$, Weight is $0.002 \mathrm{~g} / \mathrm{m}^{3}$, Sheet Resistance is $<4 \mathrm{mil}$ ( $\Omega / \mathrm{sq}$.), Coating thickness is $20 \mu \mathrm{m}$, Sintering temperature is $80 \mathrm{C}$, Boiling Temperature is $200 \mathrm{C}$, Density is $0.97 \mathrm{~g} / \mathrm{cm}^{3}$, Viscosity is $6 \mathrm{~Pa}$ s. These values were taken from the Datasheet of the graphene material provider: Ad-Nano Technologies Private Ltd.

\section{Results and discussion}

\subsection{Normal and truncated patch}

The simulated results of normal and truncated patch are shown in Table 1. From the results obtained it is clear that Gain of the truncated patch is greater than that of the normal patch and its radiation pattern is shown in Fig. 5. Also there is a change in the polarization and because of the truncation the polarization shift from linear to circular with improvement in the gain parameter.

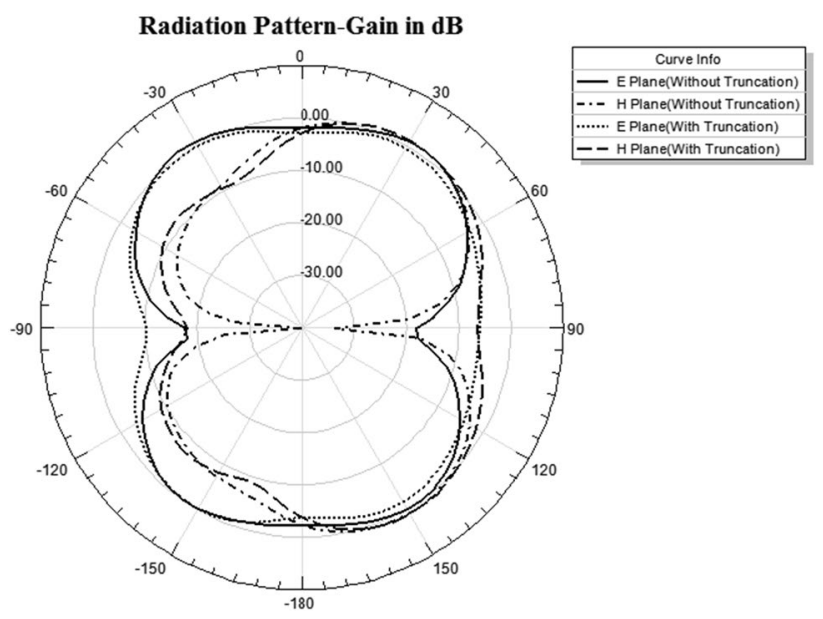

Fig. 5 Radiation pattern

Fig. 4 Graphene antenna a top view, b bottom view

Table 1 Simulation comparison of return loss, VSWR, gain and bandwidth

\begin{tabular}{lllllll}
\hline & $\begin{array}{l}\text { Resonant fre- } \\
\text { quency }(\mathrm{GHz})\end{array}$ & Return loss $(\mathrm{dB})$ & VSWR & Gain (dB) & $\begin{array}{l}\text { Return loss bandwidth } \\
(\mathrm{S} 11 \leq 10 \mathrm{~dB}) \text { in MHz }\end{array}$ & $\begin{array}{l}\text { VSWR bandwidth } \\
(\mathrm{VSWR} \leq 2) \text { in } \mathrm{MHz}\end{array}$ \\
\hline Without truncation & 2.675 & -14.5968 & 1.4578 & 4.8506 & 350.1 & 381.1 \\
With truncation & 2.545 & -11.1451 & 1.7669 & 5.3925 & 228.6 & 281.6 \\
\hline
\end{tabular}




\subsection{Return loss}

The return loss plot for simulated, fabricated copper and graphene antennas are shown in Fig. 6. Due to ground plane reduction the resonant frequency of the square patch is shifted to high frequency i.e., -14.5968 at $2.675 \mathrm{GHz}$ as shown in trace 1 . This frequency mismatch is rectified by truncation and the return loss curve is shown by trace 2 in which the frequency band is $2.545 \mathrm{GHz}$ with return loss of $-11.1451 \mathrm{~dB}$ which is nearer to ISM band. The measured return loss of copper antenna with conventional soldering and using polymer based conductive bonding composite are $-35.3707 \mathrm{~dB}$ at $2.610 \mathrm{GHz}$ and $-19.7495 \mathrm{~dB}$ at $2.525 \mathrm{GHz}$ respectively. These are shown in trace 3 and 4 . Single layer graphene resonates at $2.625 \mathrm{GHz}$ which is nearer to conventional copper antenna with return loss of $-13.2710 \mathrm{~dB}$ whereas Double layer graphene stack antenna has very good return loss of $-29.5184 \mathrm{~dB}$ at $2.580 \mathrm{GHz}$ which are shown in trace 5 and 6 respectively.

\subsection{Vswr}

Figure 7 shows the VSWR plot for all the simulated and fabricated antennas. The simulated values for normal square patch and truncated patch are 1.4578 and 1.7669 respectively. Copper antenna gave VSWR of 1.0962 with soldering and 1.2562 with polymer based conductive bonding composite. Graphene antenna shows VSWR value of 1.5723 in single layer and 1.0896 in double layer.

\subsection{Bandwidth}

Both return loss bandwidth and VSWR band width are calculated for all designed and prototyped antenna. Table 2 shows all the measured values of the antenna. From the table it is evident that copper antenna with polymer based conductive bonding composite gives broad bandwidth when compared to conventional lead soldering method. Single layer graphene antenna gives very narrow bandwidth even though it has good electrical conductivity. But double layer provides $\approx 90 \mathrm{MHz}$ bandwidth which is much greater than single layer and also greater than copper antenna with soldering connection.

Single layer of graphene printing is giving a gain of $+4.6002 \mathrm{~dB}$ and double layer of graphene successively printed without any airgap using screen printing technique is giving a gain of $+5.1000 \mathrm{~dB}$. The performance is observed as better when compared to copper material with improvement in the gain from +4.8023 to $+5.1000 \mathrm{~dB}$. This is due to the conductivity nature of the graphene conductive ink. The conductivity of copper is in the range of $10^{4}-10^{5} \mathrm{~S} / \mathrm{m}$ whereas the conductivity of graphene conductive ink material is having a value of $10^{8} \mathrm{~S} / \mathrm{m}$. This is the primary factor which defines and improves the performance of printed patch antenna structures comparatively better than that of copper material. Because of the conductivity of the material used there is an improvement in the performance of the gain parameter of the proposed design using graphene conductive ink.

The electrical conductivity of graphene is determined by 4 probe conductivity meter and it is examined at a temperature from 50 to $100{ }^{\circ} \mathrm{C}$ and it is observed that the

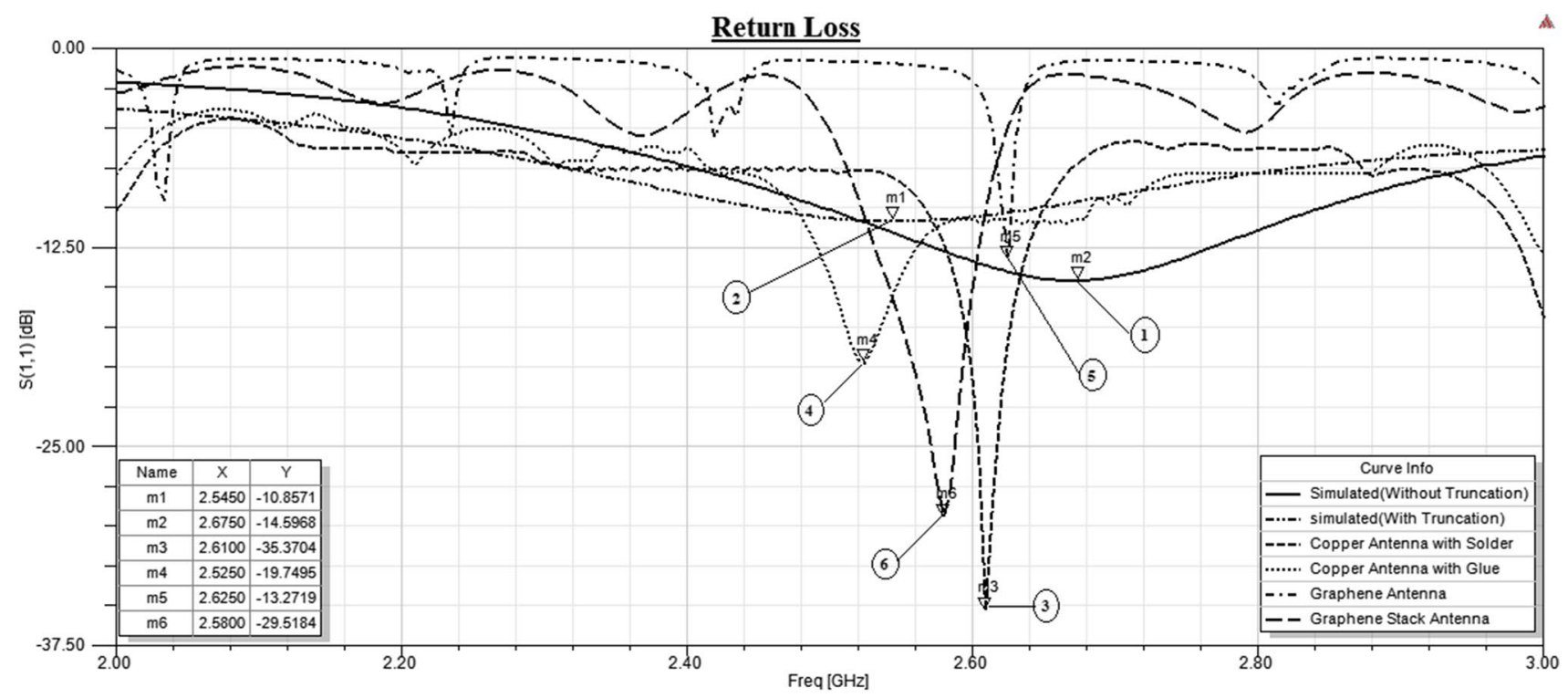

Fig. 6 Return loss plot for simulated and measured 
conductivity remains constant at $10^{8} \mathrm{~S} / \mathrm{m}$. We have examined only the solid state conductivity of the printed structures. From this the chemical potential is obtained to be $0.24 \mathrm{eV}$ using the formula

$\sigma_{\text {graphene }}=e^{17} \mu+0.0012[\mathrm{~S}]$

and with the relaxation time $\tau=0.5 \mathrm{ps}$. In [17] $0.25 \mathrm{eV}$ chemical potential is obtained for microwave frequency which is almost equal to the value obtained in this work.

Radiation efficiency is defined as the ratio of radiated power $\left(P_{r}\right)$ to accepted power $\left(P_{a}\right)$. Here we have set an input power of $1 \mathrm{~W}$ for testing purpose and it is inferred that the radiated power is measured as shown in the Table 3.

There are many forms of graphene available in the market such as graphene oxide, graphene conductive ink, single layer graphene, double layer graphene, multilayer graphene, low density graphene powder, high density graphene powder and exfoliated graphene. We are using graphene conductive ink for screen printing mechanism which will be more suitable for microwave applications such as printed patch antenna structures. The graphene

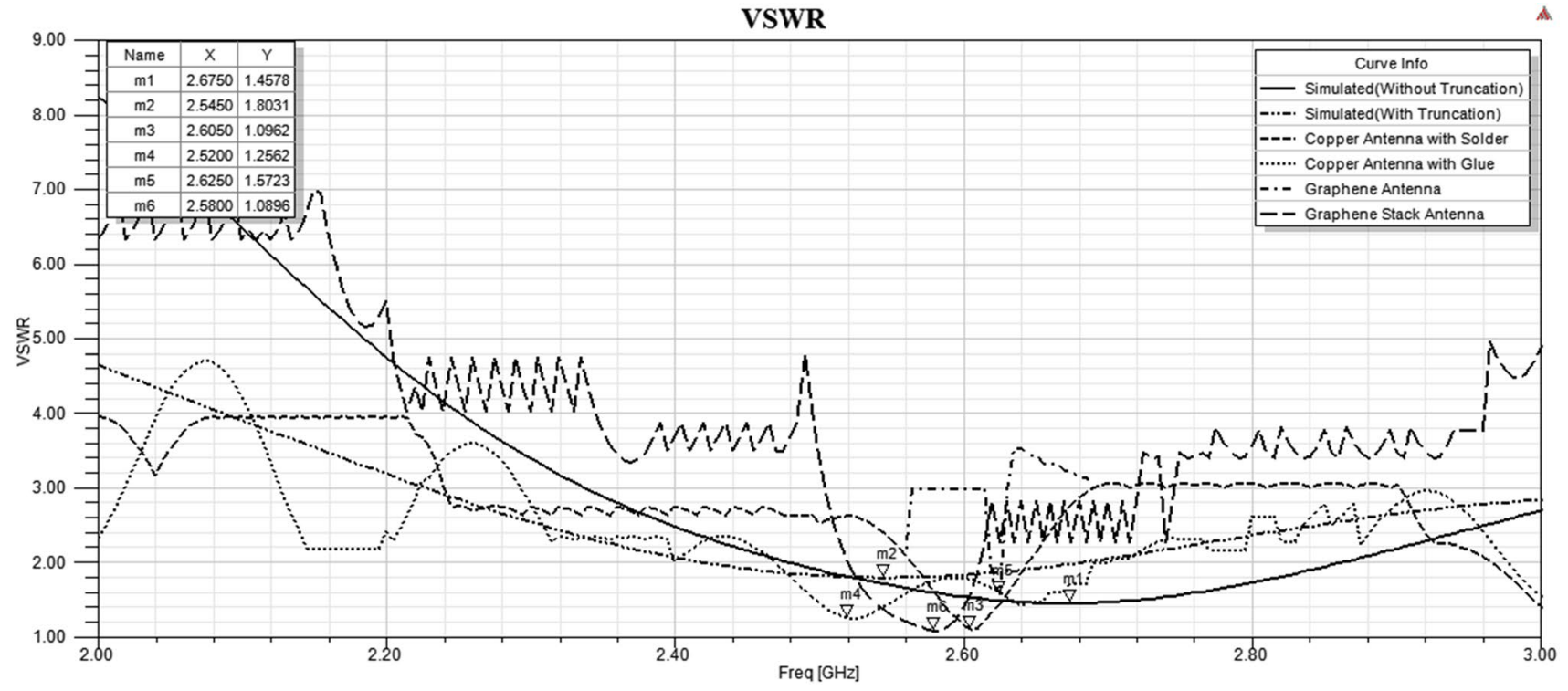

Fig. 7 VSWR plot for simulated and measured antenna

Table 2 Measured comparison of return loss, VSWR and bandwidth

\begin{tabular}{lllrrrr}
\hline & $\begin{array}{l}\text { Resonant } \\
\text { frequency } \\
\text { (GHz) }\end{array}$ & Return loss (dB) & VSWR & Gain (dB) & $\begin{array}{l}\text { Return loss band- } \\
\text { width (S11 } \leq 10 \mathrm{~dB}) \\
\text { in MHz }\end{array}$ & $\begin{array}{r}\text { VSWR bandwidth } \\
\text { (VSWR } 2) \text { in MHz }\end{array}$ \\
\hline $\begin{array}{l}\text { Copper antenna with conventional solder- } \\
\text { ing }\end{array}$ & 2.610 & -35.3704 & 1.0962 & 4.8023 & 84.4 & \\
$\begin{array}{l}\text { Copper antenna with conductive glue } \\
\text { Single layer graphene antenna }\end{array}$ & 2.525 & -19.7495 & 1.2562 & 4.6026 & 208.4 & 81.4 \\
\begin{tabular}{l} 
Double layer stacked graphene antenna \\
\hline
\end{tabular} & 2.625 & -13.2710 & 1.5723 & 4.6002 & 6.7 & 231.1 \\
\hline
\end{tabular}

Table 3 Performance comparison

\begin{tabular}{lllll}
\hline & $\begin{array}{l}\text { Input } \\
\text { power (W) }\end{array}$ & $\begin{array}{l}\text { Accepted } \\
\text { power (W) }\end{array}$ & $\begin{array}{l}\text { Radiated } \\
\text { power (W) }\end{array}$ & $\begin{array}{l}\text { Radiation } \\
\text { efficiency } \\
(\%)\end{array}$ \\
\hline Copper antenna with conventional soldering & 1.0 & 0.8301 & 0.6890 & 83.0 \\
Copper antenna with conductive glue & 1.0 & 0.8438 & 0.6708 & 79.5 \\
Single layer graphene antenna & 1.0 & 0.8738 & 0.6334 & 72.5 \\
Double layer stacked graphene antenna & 1.0 & 0.8279 & 0.6921 & 83.6 \\
\hline
\end{tabular}


conductive ink will comparatively perform better than graphene for microwave application.

The proposed design will be more suitable for ISM band applications, Wi-Fi and indoor communication modes, as external power absorber in rectenna setups for microwave wireless power harvesting.

\section{Conclusion}

In this project, we replaced conventional copper based antenna with carbon allotrope based Graphene material and it is observed that the effect of Graphene in function of the proposed antenna design is performing better compared to that of the copper. In this experimental trail we have fabricated successive lattice structure with uniform bonding to achieve stacking performance of antenna. The effect of different bonding materials for electrical conductivity was also performed inferred that using material based conductive polymer substance will allow suitable bands which is absent in terms of using Lead based soldering technique. The proposed stack structure is performing better in terms of Return Loss, VSWR and Gain when compared to the same structure with copper so we conclude replacing the copper with Graphene composite will be more fruitful in patch antenna structures.

\section{Compliance with ethical standards}

Conflict of interest The authors declare that they have no conflict of interest

\section{References}

1. Balanis CA (2005) Antenna Theory Analysis and Design, 3rd edn. Wiley, New York

2. Kaur N, Sivia JS (2016) On the design defected ground plane based $\mathrm{L}$ slotted microstrip patch antenna for $\mathrm{C}$ band applications. In: International conference on research advances in integrated navigation systems (RAINS)

3. Ndujiuba Charles U, Ilesanmi Oluwafemi A, Agboje Oboyerulu $E$ (2017) Effect of edge-cut dimensions on the electrical parameters of an inset-fed rectangular microstrip patch antenna with partial ground. Int J Netw Commun 7(2):40-46

4. Nguyen MT, Kim B, Choo H, Park I (2010) Effects of ground plane size on a square microstrip patch antenna designed on a low-permittivity substrate with an air gap. In: International workshop on antenna technology (iWAT)

5. Salleh $S M$, Jusoh $M$, Ismail $A H$, Kamarudin MR, Nobles $P$, Rahim MKA, Soh PJ (2017) Textile antenna with simultaneous frequency and polarization reconfiguration for WBAN. IEEE Access 6:7350-7358

6. Kurniawan F, Sri Sumantyo JT, Gao S, Ito K, Santosa CE (2018) Square-shaped feeding truncated circularly polarised slot antenna. IET Microw Antennas Propag 12(8):1279-1286

7. Sacharias SA, Suganthi S (2016) Performance improvement of triple band truncated spiked triangular patch antenna. In: International conference on emerging trends in engineering, technology and science (ICETETS)

8. Kurniawan F, Sumantyo JTS, Munir A (2017) Effect of truncation shape against axial ratio of left-handed circularly polarized $X$-band antenna. In: 15th international conference on quality in research (QiR) : international symposium on electrical and computer engineering

9. Sekra P, Bhatnagar D, Saxena VK, Saini JS (2009) Single feed circularly polarized edge truncated elliptical microstrip antenna. In: International conference on emerging trends in electronic and photonic devices and systems

10. Torrisi F, Hasan T, Wu W, Sun Z, Lombardo A, Kulmala TS, Ferrari AC (2012) Inkjet-printed graphene electronics. ACS Nano 6(4):2992-3006

11. Pan K, Fan Y, Leng T, Li J, Xin Z, Zhang J, Hu Z (2018) Sustainable production of highly conductive multilayer graphene ink for wireless connectivity and loT applications. Nat Commun 9(1):5197

12. Ying Liu Hu, Liu Ming Wei, Gong Shuxi (2014) A novel slot Yagilike multilayered antenna with high gain and large bandwidth. IEEE Antennas Wirel Propag Lett 13:790-793

13. Shaik S, Dwivedi RP (2017) High gain stacked patch antenna with circular polarization for wireless applications. In: International conference on nextgen electronic technologies: silicon to software (ICNETS2)

14. Chae S-C, Ahn B, Yeo T-D, Yu J-W (2017) An automotive stacked ceramic patch antenna with an integrated GNSS and SDARS antenna. In: International symposium on antennas and propagation (ISAP)

15. Kortright MAB, Waldstein SW, Simons RN (2017) Reconfigurable wideband circularly polarized stacked square patch antenna for cognitive radios. In: Cognitive communications for aerospace applications workshop (CCAA)

16. Prasanna R, Masoodhu Banu NM (2019) Effect of copper and graphene material on bow-tie structured antenna for $12 \mathrm{GHz}$ application. Radioelectron Commun Syst 62(4):189-194

17. Perruisseau-Carrier J, Tamagnone M, Gomez-Diaz JS, Carrasco E (2013) Graphene antennas: can integration and reconfigurability compensate for the loss? In: European microwave conference

Publisher's Note Springer Nature remains neutral with regard to jurisdictional claims in published maps and institutional affiliations. 